\title{
Spawanie złączy doczołowych rur ze staliwa G17CrMo5-5 do pracy w podwyższonej temperaturze
}

\author{
Tube butt welding of cast steel G17CrMo5-5 \\ to work at elevated temperature
}

\section{Streszczenie}

W artykule przedstawiono podstawowe zagadnienia związane ze spawalnością i spawaniem staliwa G17CrMo5-5 przeznaczonego do pracy w podwyższonej temperaturze. Staliwo to może być wykorzystane do wykonania komory zaworowej turbiny parowej.

W pracy opisano sposoby przygotowania materiału do spawania oraz proces spawania metodami TIG/MMA i obróbkę cieplną po spawaniu. Próby spawania przeprowadzono w pozycjach PH i PC. Próbne złącza poddano badaniom niszczącym w zakresie: badanie pracy łamania, badanie rozkładu twardości oraz wykonano badania makroskopowe. W otrzymanych wynikach badań zauważalne są różnice w właściwościach złączy wykonywanych w różnych pozycjach co związane jest z ilością ciepła wprowadzonego do złącza podczas procesu spawania.

Słowa kluczowe: staliwo, spawanie, energia liniowa

\section{Abstract}

The article presents basic issues related to weldability and welding of cast steel G17CrMo5-5 designed for use at elevated temperatures. This cast steel can be used to perform the valve chamber of the steam turbine .

This paper describes how to prepare material for welding and TIG welding process / MMA and post-weld heat treatment. Welding tests carried out in positions $\mathrm{PH}$ and $\mathrm{PC}$. The trial joints were tested destructive in terms of: breaking work testing, hardness distribution testing and macroscopic tests were performed. There are noticeable differences in the obtained tests results in the properties of joints made at different positions which is related to the amount of heat introduced into the connector during the welding process.

Keywords: cast steel, welding, heat input

\section{Wstęp}

W przemyśle energetycznym oprócz elementów stalowych stosowane są również element konstrukcyjne wykonane ze staliwa. Wykonuje się z nich między innymi kadłuby turbin, komory zaworowe, trójniki itp. Elementy odlewane w znaczący sposób mogą ułatwić proces wytwórczy, stanowią jednak podobnie jak stale przeznaczone do pracy w podwyższonej temperaturze pewne wyzwanie dla inżyniera spawalnika [1 $\div 2]$.

Staliwo G17CrMo5-5 to niskostopowy materiał do pracy $\mathrm{w}$ podwyższonych temperaturach, głównie stosowany w energetyce, $\mathrm{np}$. do wykonywania korpusów turbin parowych [3]. Staliwo G17CrMo5-5 wymaga podgrzewania wstępnego przed spawaniem oraz określonej energii liniowej spawania, a także obróbki cieplnej po spawaniu. Pozwala to wykonanie złączy spawanych spełniających wymagania odpowiednich przepisów EN ISO 15614-1. Zawartość węgla na poziomie 0,16 \% można uznać za niską natomiast $\mathrm{w}$ połączeniu z zawartością chromu ma istotny wpływ na spawalność (Tabica I). Węgiel i chrom będą wpływać na utwardzenie SWC i mogą doprowadzić do powstania

stref zahartowanych w złączu. Dodatek manganu w wysokości 0,63\% nie pogarsza spawalności. Jego zadaniem jest nadanie odpowiedniej wytrzymałości staliwa. Trzeba jednak nadmienić, że nawet niewielkie zawartości siarki ifosforu znacznie pogarszają spawalność, która w przypadku staliw

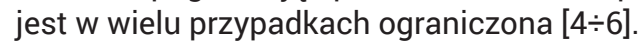

Tablica I. Skład chemiczny staliwa G17CrMo5-5 według analizy wytopowej [wag. \%].

Table I. Chemical composition of cast steel G17CrMo5-5 according to analysis of the heat

\begin{tabular}{|c|c|c|c|c|c|c|}
\hline C & Mn & Cr & Mo & Si & P & S \\
\hline 0,15 & 0,63 & 1,22 & 0,45 & 0,49 & 0,012 & 0,007 \\
\hline
\end{tabular}

Grubość łączonych elementów jest jednym z istotnych czynników wpływających na dobór parametrów technologicznych. Wraz ze wzrostem grubości materiału i wzrostem równoważnika węgla należy stosować odpowiednie podgrzewanie wstępne. 
Z technologiczne punktu widzenia kształt fazy spawalniczej ma istotny wpływ na jakość powstałego złącza. Im mniejszy kąt spawania tym mniejsze zużycie stopiwa i mniejsze naprężenia, ale zbyt małe pochylenie może przyczynić się do powstawania przyklejeń i utrudnić poprawne manipulowanie elektrodą. Kąt pochylenia fazy spawalniczej ma również wpływ na kierunek odprowadzania ciepła i współczynnik kształtu spoiny.

W przypadku stosowania metod spawania TIG/MMA pozycja spawania odgrywa dużą rolę. Jednym z czynników utrudniającym spawanie w pozycjach przymusowych jest siła grawitacji. Aby zmniejszyć skutki tej siły zaleca się spawanie z odpowiednią prędkością i techniką spawania. W zależności od pozycji spawania należy stosować odpowiednie zakresy natężeń prądu. Zwykle najwięcej ciepła wprowadza się w pozycji spawania PF dla blachy, a PH dla rury, natomiast najmniejsza ilość ciepła wprowadzona jest w pozycji PC.

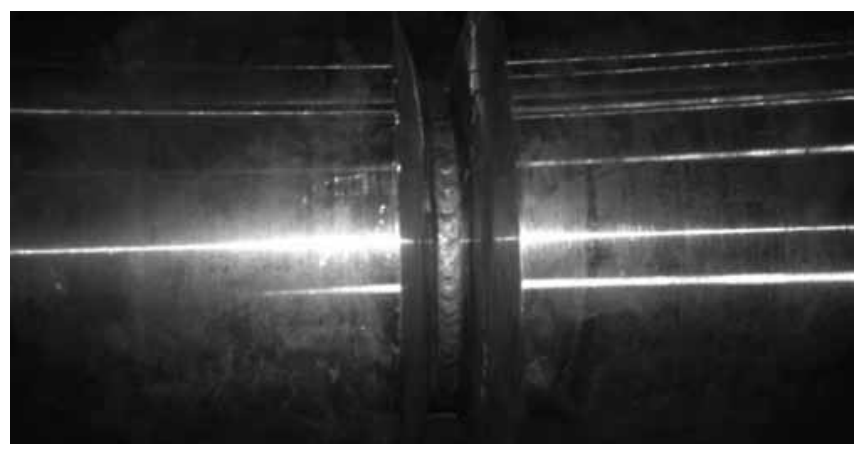

Rys. 1. Widok warstwy graniowej od strony lica. Pozycja spawania PH Fig. 1. View layer of back weld. PH welding position

\section{Próby spawania}

Materiał podstawowy do spawania o grubości $45 \mathrm{~mm}$ i ukosowaniu na $U$ z progiem do $2 \mathrm{~mm}$, przygotowano poprzez obróbkę mechaniczną. Fazy spawalnicze przed spawaniem sprawdzono badaniami penetracyjnymi w celu upewnienia się, że na powierzchni nie ma pęknięć. Próbne złącza wykonano w pozycjach PC i PH (rys. 1). Materiałami dodatkowymi, wykorzystanymi do spawania próbnych złączy były materiały firmy Lincoln Electric. Do spawania użyto pręt LNT 19 oraz elektrody SL 19 G o średnicach 2,5; 3,2; 4; $5 \mathrm{~mm}$. Temperaturę podgrzewania wstępnego ustalono na $150{ }^{\circ} \mathrm{C}$, a temperaturę międzyściegową na $350{ }^{\circ} \mathrm{C}$. W pierwszej kolejności rury podgrzewano wstępnie do wykonania spoin sczepnych. Spoiny sczepne metodą TIG wykonano co 90 stopni. Warstwę graniową wykonano metodą TIG. Kolejne warstwy wykonano elektrodami otulonymi o składzie zbliżonym do składu materiału podstawowego. Po spawaniu złącza próbne poddano obróbce cieplnej przez 5 godzin w temperaturze $700^{\circ} \mathrm{C}$. Podstawowe parametry procesu spawania przedstawiono w tablicach II i III.

\section{Wyniki badań złączy próbnych}

Głównym celem pracy było określenie właściwości złączy doczołowych rurowych ze staliwa G17CrMo5-5 wykonywanych w dwóch różnych pozycja. Przed przystąpieniem do badań niszczących wszystkie złącza próbne poddano badaniom nieniszczącym VT, PT i UT. Wszystkie badane złącza uzyskały poziom jakości B według normy EN ISO 5817. W dalszej

Tablica II. Parametry procesu spawania w pozycji PC

Table II. Parameters of welding processes in position PC

\begin{tabular}{|c|c|c|c|c|c|}
\hline Ścieg & $\begin{array}{c}\text { Proces } \\
\text { spawania }\end{array}$ & $\begin{array}{c}\text { Wymiar } \\
\text { spoiwa } \\
{[\mathrm{mm}]}\end{array}$ & $\begin{array}{c}\text { Natężenie } \\
\text { prądu } \\
\text { spawania } \\
{[\mathrm{A}]}\end{array}$ & $\begin{array}{c}\text { Napięcie } \\
\text { łuku } \\
{[\mathrm{V}]}\end{array}$ & $\begin{array}{c}\text { Energia } \\
\text { liniowa } \\
{[\mathrm{kJ} / \mathrm{mm}]}\end{array}$ \\
\hline 1 & 141 & 2,4 & $100-110$ & $11-13$ & $0,88-1,02$ \\
\hline 2 & 111 & 2,5 & $80-100$ & $22-24$ & $0,61-0,65$ \\
\hline $3-5$ & 111 & 3,2 & $110-130$ & $21-23$ & $0,92-1,04$ \\
\hline $6-23$ & 111 & 4 & $130-150$ & $22-25$ & $0,73-1,26$ \\
\hline $24-49$ & 111 & 5 & $160-190$ & $22-26$ & $0,65-1,16$ \\
\hline $50-59$ & 111 & 4 & $130-150$ & $23-25$ & $0,54-0,61$ \\
\hline
\end{tabular}

Tablica III. Parametry procesu spawania w pozycji PH

Table III. Parameters of welding processes in position $\mathrm{PH}$

\begin{tabular}{|c|c|c|c|c|c|}
\hline Ścieg & $\begin{array}{c}\text { Proces } \\
\text { spawania }\end{array}$ & $\begin{array}{c}\text { Wymiar } \\
\text { spoiwa } \\
{[\mathrm{mm}]}\end{array}$ & $\begin{array}{c}\text { Natężenie } \\
\text { prądu } \\
\text { spawania } \\
{[\mathrm{A}]}\end{array}$ & $\begin{array}{c}\text { Napięcie } \\
\text { fuku } \\
{[\mathrm{V}]}\end{array}$ & $\begin{array}{c}\text { Energia } \\
\text { liniowa } \\
{[\mathrm{kJ} / \mathrm{mm}]}\end{array}$ \\
\hline 1 & 141 & 2,4 & $95-110$ & $11-13$ & $0,67-0,73$ \\
\hline 2 & 111 & 2,5 & $80-100$ & $20-24$ & $1,87-2,03$ \\
\hline 3 & 111 & 3,2 & $110-130$ & $21-23$ & $2,86-3,68$ \\
\hline $4-7$ & 111 & 4 & $130-150$ & $22-25$ & $2,84-3,93$ \\
\hline $8-15$ & 111 & 5 & $160-190$ & $22-26$ & $2,82-3,96$ \\
\hline $16-18$ & 111 & 4 & $130-150$ & $22-25$ & $1,61-3,00$ \\
\hline $19-23$ & 111 & 3,2 & $100-120$ & $23-25$ & $1,25-1,95$ \\
\hline
\end{tabular}


kolejności przeprowadzono badania niszczące skupiając się na badaniach makroskopowych, badaniu twardości oraz badaniu pracy łamania. Z przygotowanych złączy spawanych w pozycjach PC oraz PH wycięto próbki do badań makroskopowych, na których przeprowadzono również badania rozkładu twardości na przekroju poprzecznym złącza (rys. 2, 3).

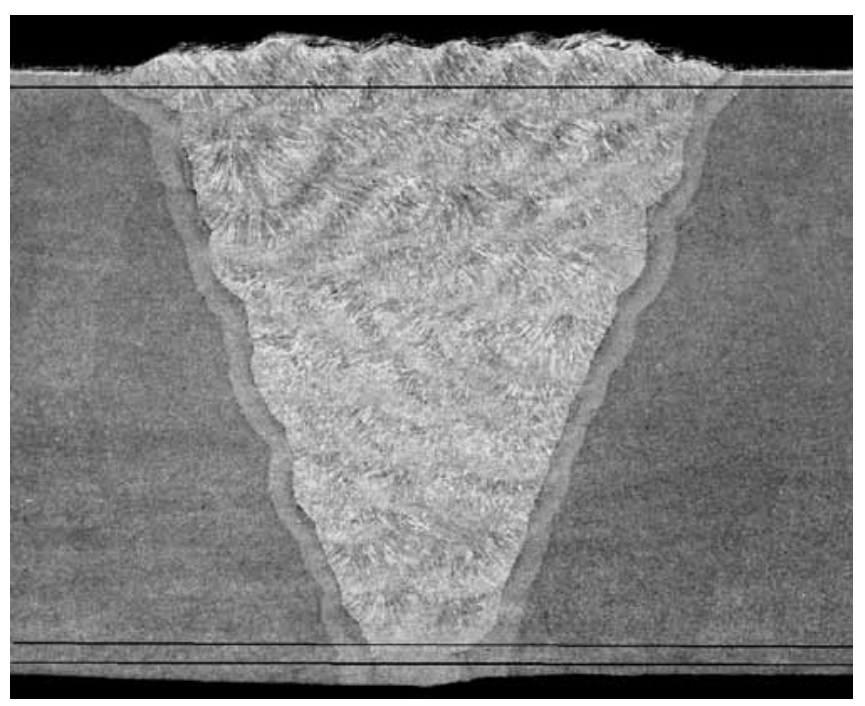

Rys. 2. Widok złącza spawanego w pozycji PC

Fig. 2. View of joint welded in PC position

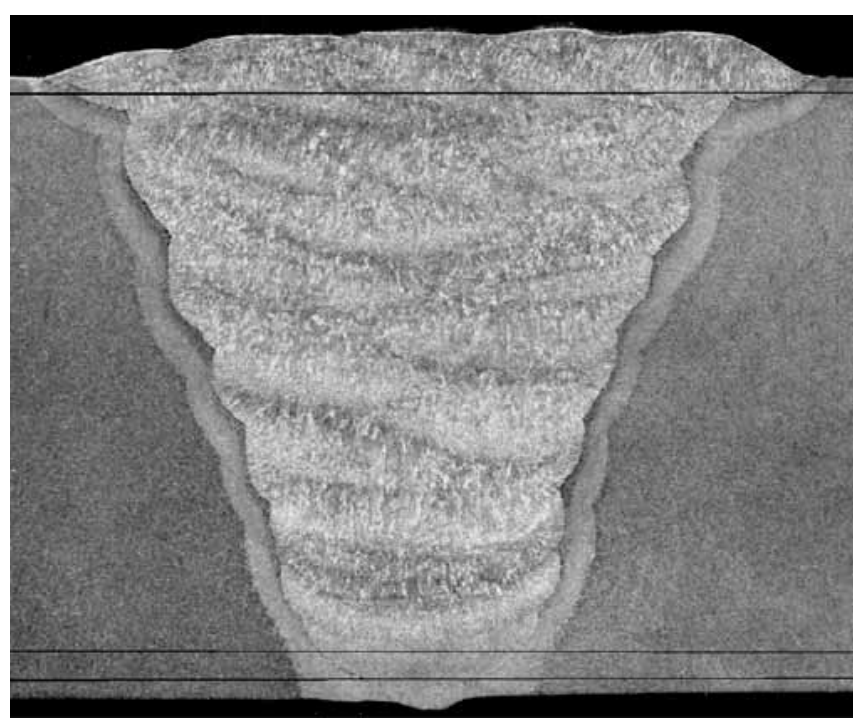

Rys. 3. Widok złącza spawanego w pozycji PH

Fig. 3. View of joint welded in $\mathrm{PH}$ position

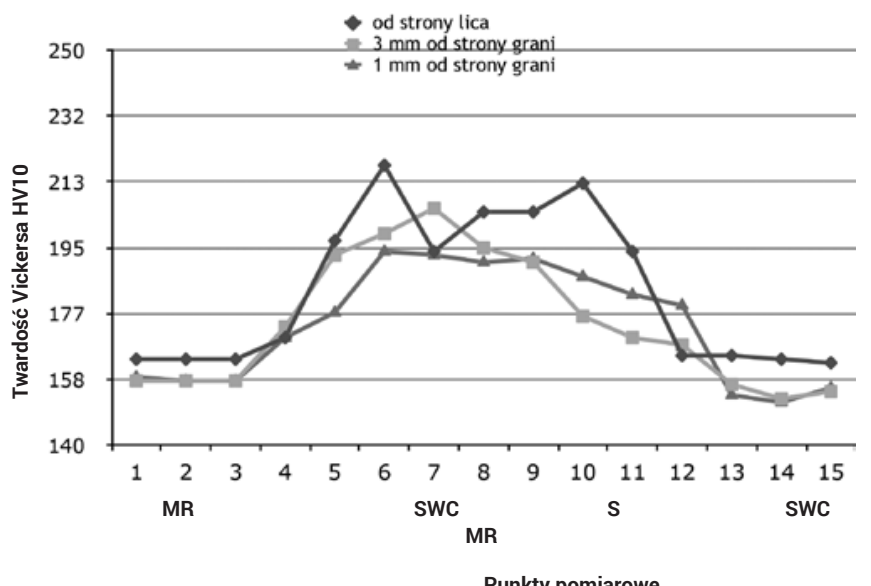

Rys. 4. Rozkład twardości złącza spawanego w pozycji PC

Fig. 4. Hardness distribution in joint welded in PC position
Badania makroskopowe potwierdziły prawidłowy układ ściegów oraz kształt złącza, które są charakterystyczne dla pozycji spawania PH oraz PC. Badania rozkładu twardości w badanych złączach pokazano na rysunkach 4 i 5. W każdym z analizowanych złączy twardość nie przekraczała dopuszczalnej wartości 350HV10. Rozkład twardości jest podobny dla spawania w pozycji PC i PH, gdzie maksymalne zmierzone twardości są na poziomie $220 \mathrm{HV} 10$ w warstwie licowej złącza. Dla złącza spawanego w pozycji PC zauważalne są większe twardości w spoinie od strony grani jak również bardziej nieregularny rozkład twardości w porównaniu do złącza spawanego w pozycji PH. Nie są to jednak różnice, które wpływałby w znaczący sposób na właściwości porównywanych złączy.

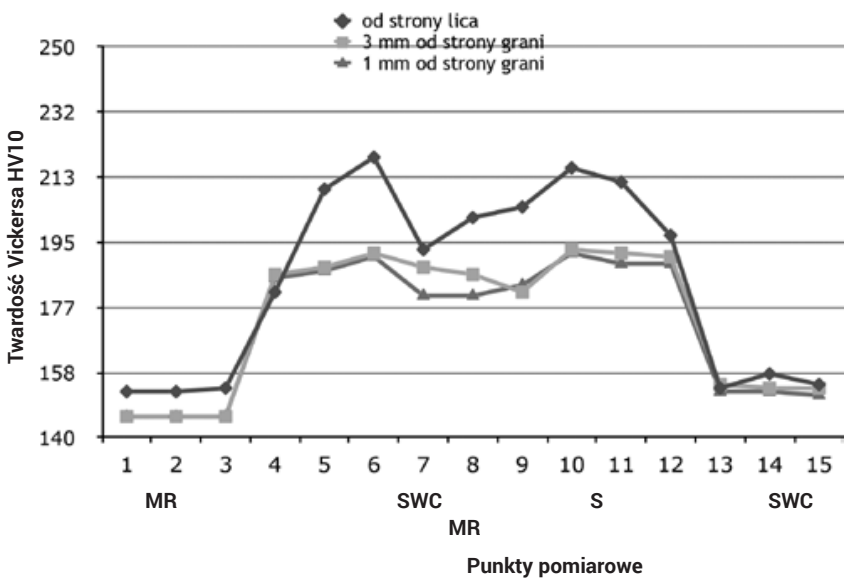

Rys. 5. Rozkład twardości złącza spawanego w pozycji PH

Fig. 5. Hardness distribution in joint welded in $\mathrm{PH}$ position

Większe różnice we właściwościach badanych złączy zostały ujawnione podczas badań nad pracą łamania (rysunek 6-7). Przygotowane próbki Charpy $V$ zostały poddane badaniom w temperaturze otoczenia i przyjęto $27 \mathrm{~J}$ jako minimalną wartość w czasie tej próby. Zauważalnie wyższe wyniki pracy łamania zostały zanotowane dla spoiny w złączu spawanym w pozycji PC. Różnie w pracy łamania spoin sięgają w tym wypadku prawie $40 \mathrm{~J}$.

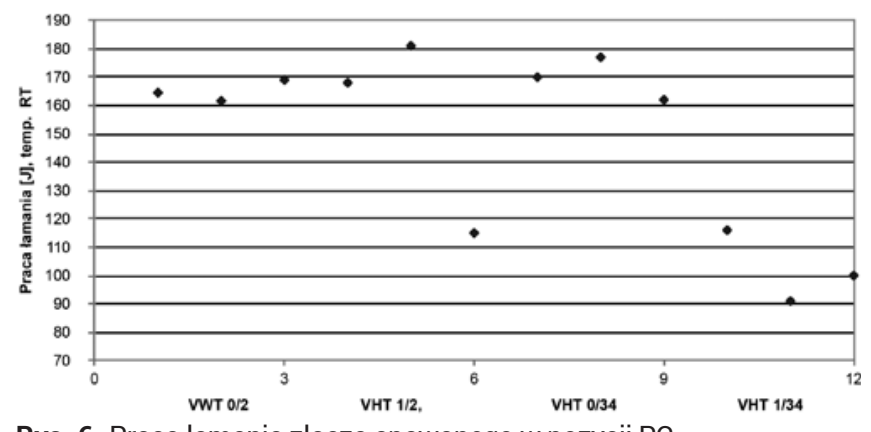

Rys. 6. Praca łamania złącza spawanego w pozycji PC

Fig. 6. Impact strength of joint welded in $\mathrm{PC}$ position

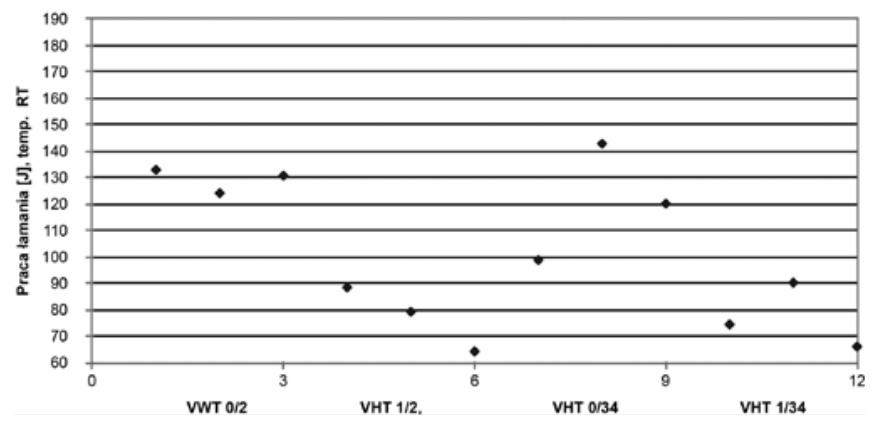

Rys. 7. Praca łamania złącza spawanego w pozycji $\mathrm{PH}$

Fig. 7. Impact strength of joint welded in $\mathrm{PH}$ position 
Jeszcze większe różnice są widoczne dla próbek, w których karb nacięto w strefie wpływu ciepła. Dużo wyższe wartości pracy łamania są osiągane przez próbki pochodzące ze złącza spawanego w pozycji PC i dla nich też można zaobserwować dużo mniejszy rozrzut otrzymywanych wyników. Spawanie w pozycji PC wąskimi ściegami wprowadziło do złącza dużo mniej ciepła co w sposób korzystny przełożyło się na wyniki pracy łamania. Spawanie w pozycji PH spowodowało dużo większe zmiany w strukturze i właściwościach spoiny jak również strefy wpływu ciepła. Należy podkreślić, że pomimo zauważalnych różnic złącza spawane w analizowanych pozycjach spełniają minimalne wymagania 27J.

\section{Podsumowanie}

Spawanie rur ze staliwa G17CrMo5-5 wymaga od spawaczy jak i nadzoru spawalniczego dobrego przygotowania merytorycznego jak również doświadczenia produkcyjnego. Odpowiedni sposób ukosowania złącza na U oraz odpowiedni wybór pozycji spawania może w znaczący sposób przyczynić się do wykonania złącza wysokiej jakości. W analizowanych przypadkach złącza spawane w pozycji PC oraz PH spełniły minimalne i maksymalne wymagania odnośnie twardości i pracy łamania. Z tego punktu widzenia pozycja spawania nie wpływa na końcową ocenę jakość złącza spawanego. Należy jednak podkreślić duże różnice jakie zanotowano w pracy łamania pomiędzy złączami wykonanymi w pozycji PC i pozycji PH. Ograniczona ilość ciepła jaką wprowadzono w pozycji PC, pomimo ułożenia większej liczby ściegów, wpłynęła w sposób korzystny na pracę łamania w stosunku do wartości uzyskanych dla złącza wykonanego w pozycji PH. Końcowa obróbka cieplna w temperaturze $700^{\circ} \mathrm{C}$ nie zniwelowała różnic w strukturze materiału jaka została wywołana procesem spawania w analizowanych pozycjach. Z punktu widzenia właściwości wytrzymałościowych lepszym wyborem jest spawanie w pozycji PC, pomimo większych kosztów spawania.

\section{Literatura}

[1] Dobrzański L.A; Podstawy Nauki o materiałach i metaloznawstwo, WNT, Warszawa 2002.

[2] Perzyk M., S Waszkiewicz S., Kaczorowski M., Jopkiewicz A.; Odlewnictwo, WNT, Warszawa 2000

[3] PN-EN 10213:2010 Odlewy staliwne do pracy pod ciśnieniem.

[4] Wodecki D.; Technologie naprawy odlewów korpusów oraz uzbrajania komór zaworowych turbin wielkogabarytowych wykonanych ze stali energetycznych, Politechnika Częstochowska, Częstochowa 2010.
[5] R. Bęczkowski, M. Gucwa: Wybrane aspekty napraw odlewów korpusów urządzeń energetycznych, Przegląd Spawalnictwa, Vol. 87, Nr 5, s. 10-109, 2015.

[6] M. Żuk: Naprawa odlewów staliwnych typu duplex GX2CrNiMoCu25-6-3-3 metodą MAG drutem proszkowym, Przegląd Spawalnictwa, Vol. 87, Nr 5, s. 9-14, 2015. 